\title{
Facebook and mental wellbeing: a crossover randomised
}

\section{controlled study [version 1; peer review: 1 approved with}

\section{reservations, 1 not approved]}

\section{Achim Wolf}

Department of Psychiatry, Warneford Hospital, University of Oxford, Oxford, OX3 7JX, UK

\author{
V1 First published: 09 Jun 2016, 5:1311 \\ https://doi.org/10.12688/f1000research.8835.1 \\ Latest published: 09 Jun 2016, 5:1311 \\ https://doi.org/10.12688/f1000research.8835.1
}

\section{Abstract}

Objective: To study the effect of reducing Facebook use for two weeks on self-reported mental wellbeing in a student population. Methods: Students at the University of Oxford $(n=78)$ participated in a randomised crossover study which consisted of two consecutive twoweek periods of minimised Facebook use, followed by normal Facebook use, or vice-versa. Participants were evaluated after each two-week period using the 14-item Warwick-Edinburgh Mental WellBeing Scale (WEMWBS), and completed questionnaires about their Facebook use. Differences in WEMWBS scores were evaluated using a paired t-test.

Results: Of those enrolled, 57 (73\%) students completed the entire study. 93\% reported reduced Facebook use during the intervention period. When limiting their Facebook use, participants had an average WEMWBS score of 46.0, compared to 43.7 during the control period, equating to a difference of 2.3 points (95\% CI: 0.4 to $4.2 ; p=0.016$; Cohen's $d=0.33$ ). There were no significant differences in dropout between the two groups $(p=0.3)$, or differences in effect when stratifying by gender $(p=0.9)$ or relationship status $(p=0.6)$.

Conclusion: Reducing Facebook use may be an effective intervention for improving mental wellbeing in university students. Future studies should examine effects in other participant groups, and use longer follow-up periods.

Keywords

Facebook, mental wellbeing, randomised controlled study, WEMWBS
Open Peer Review

\begin{tabular}{lcc} 
Approval Status & ? \\
& 1 & 2 \\
\hline version 1 & $?$ & $\times$ \\
09 Jun 2016 & view & view
\end{tabular}

1. Shahadat Uddin, University of Sydney, Sydney, Australia

2. Scottye J. Cash, The Ohio State Univeristy,

Columbus, USA

Any reports and responses or comments on the article can be found at the end of the article. 
Corresponding author: Achim Wolf (achim.wolf@psych.ox.ac.uk)

Competing interests: No competing interests were disclosed.

Grant information: The author(s) declared that no grants were involved in supporting this work.

Copyright: $(2016$ Wolf A. This is an open access article distributed under the terms of the Creative Commons Attribution License, which permits unrestricted use, distribution, and reproduction in any medium, provided the original work is properly cited. Data associated with the article are available under the terms of the Creative Commons Zero "No rights reserved" data waiver (CCO 1.0 Public domain dedication).

How to cite this article: Wolf A. Facebook and mental wellbeing: a crossover randomised controlled study [version 1; peer review: 1 approved with reservations, 1 not approved] F1000Research 2016, 5:1311 https://doi.org/10.12688/f1000research.8835.1

First published: 09 Jun 2016, 5:1311 https://doi.org/10.12688/f1000research.8835.1 


\section{Introduction}

Facebook is the largest online social networking service with around 1.1 billion monthly active users ${ }^{1}$.

Previous work has come to different conclusions on the effects of Facebook on mental wellbeing ${ }^{2,3}$. Despite a growing body of research surrounding the effects and implications of Facebook's popularity ${ }^{4}$, no research has used experimental methods to examine the Facebook and mental wellbeing relationship, and uncertainty around causality remains.

To address this, we have conducted an experimental study using a crossover randomised design. Students at the University of Oxford $(n=78)$ were asked to limit their Facebook use for two weeks and complete questionnaires on their mental wellbeing.

\section{Methods}

\section{Study design}

This study used a crossover design with simple randomisation (1:1 ratio), involving a two-week period with minimal Facebook use, and a two-week control period. No changes were made to the study protocol after receiving ethics approval through the University of Oxford's Medical Sciences Interdivisional Research Ethics Committee (Ref\#: MSD-IDREC-C1-2014-035), which was granted before commencement of the study. Trial registration was completed retrospectively through the Australian New Zealand Clinical Trials Registry (Ref\#: ACTRN12614000959673, www. anzctr.org.au/Trial/Registration/TrialReview.aspx?id=367015).

\section{Participants}

Participants were recruited between March 27 and May 25, 2014 and had to be full-time students at the University of Oxford, aged over 18, and regular (daily) Facebook users. No exclusion criteria were used. Students were recruited through adverts in student newsletters and Facebook pages, and departmental mailing lists. They were followed up for four weeks, with follow-ups starting on March 27, 2014 and ending June 22, 2014. There was no face-to-face contact between participants and researchers, or compensation for participants.

Eligibility data, informed consent, and questionnaire answers were obtained electronically. To confirm eligibility, students had to register with a valid University of Oxford email address.

\section{Intervention}

At the beginning of the intervention period, participants were asked to "restrict [their] Facebook use as much as possible for two weeks" and were told "During this time, please avoid using Facebook, including through mobile phones, tablets, and computers." At the beginning of the control period, participants were told they "can use Facebook as much as [they] want" for two weeks. Participants were sent weekly reminders. Facebook use was measured through self-reporting only.

After each two-week period participants were sent links with questionnaires, and were asked to complete them regardless of whether they had followed the instructions given to them.

\section{Outcomes}

The primary outcome is within-individual differences in WarwickEdinburgh Mental Well-Being Scale (WEMWBS) score between the two periods. WEMWBS is a 14-item measure of positive mental wellbeing which has been validated in UK student populations ${ }^{5}$. Secondary outcomes were stratification by two variables: gender, and relationship status.

\section{Sample size}

The sample size of 78 was calculated assuming a power of 0.8 , an $\alpha$ of 0.05 , a minimal detectable difference in means of 2 points in WEMWBS score, a $20 \%$ dropout rate, and a standard error of measurement (SEM) of 2.78 (mean of the five SEMs reported in Maheswaran et al. ${ }^{6}$ ).

\section{Randomisation}

Participants were randomised on a rolling basis after completing the informed consent form, using the rand() function in Excel 2013 (v.15.0). At randomisation, no data other than the participant's email address had been collected. Participants were not blinded to group allocation.

\section{Statistical methods}

The statistical significance of the primary outcome was calculated using a paired t-test. Only participants who completed both sets of questionnaires were entered in this analysis.

In a sensitivity analysis, all observations were entered into a regression analysis using Stata's clustered sandwich estimator (vce(cluster) function) to allow for within-participant correlation in data with repeated observations on individuals ${ }^{7}$, and to minimise missingness.

We present self-reported descriptive statistics on age, gender, relationship status, and whether participants reduced their use during the intervention period.

For secondary outcomes, we stratified analyses by gender (female vs. male) and relationship status (single vs. in a relationship).

All analyses were done in Stata, version 12. Observations were entered according to group allocation, following an intentionto-treat approach. Statistical assumptions for paired t-tests were tested using a histogram of the differences in scores (Assumption of Normality, Supplementary figure 1) and by plotting differences in scores against average scores (Supplementary figure 2).

\section{Results}

Participants

At randomisation, 40 participants were allocated to Group $\mathrm{AB}$ and 38 to Group BA. Two-thirds of participants were female, $46 \%$ were single. There was no significant difference in dropout between Group AB and Group BA (Table 1).

During the intervention period 25/27 (93\%) in Group AB and 28/30 (93\%) in Group BA reported reduced Facebook usage ('less than usual' or 'much less than usual'). 


\section{Outcomes}

Participants obtained average WEMWBS scores of $46.0(95 \%$ CI: 44.3 to 47.7$)$ during the intervention period, and $43.7(95 \%$ CI: 41.7 to 45.7$)$ during the control period. The average difference was 2.3 points ( $95 \%$ CI: 0.4 to $4.2, p=0.016$ ). This corresponds to a Cohen's $d$ of 0.33 (SD of difference $=7.0$ ).

In a sensitivity analysis additionally including those with follow-up at 2 weeks only, the average difference in scores was 2.6 points (95\% CI: 0.7 to $4.5, \mathrm{p}=0.009$ ).

We found no significant differences in effect by gender or relationship status (Table 2 ).
Dataset 1. Raw data of facebook and mental wellbeing analysis

http://dx.doi.org/10.5256/f1000research.8835.d124806

The raw data of the analysis on Facebook and metal wellbeing are provided. The text file contains legends by column.

\section{Discussion}

In this crossover randomised study, we analysed the effects of reducing Facebook use on mental wellbeing. This is the first randomised study to look at the relationship between Facebook use and mental wellbeing. We find that participants had an average 2.3 point higher WEMWBS score after being asked to limit their

Table 1. Participant information.

\begin{tabular}{|c|c|c|}
\hline & Group AB, $\mathbf{n}=\mathbf{4 0}$ & Group BA, $\mathbf{n}=\mathbf{3 8}$ \\
\hline Follow-up & \\
\hline At 2 and 4 weeks & $27(68 \%)$ & $30(79 \%)$ \\
\hline At 2 weeks only & $4(10 \%)$ & $1(3 \%)$ \\
\hline None & $9(22 \%)$ & $7(18 \%)$ \\
\hline Gender & & \\
\hline Male & & $4(13 \%)$ \\
\hline Female & $12(44 \%)$ & $25(83 \%)$ \\
\hline Other & $13(48 \%)$ & $1(3 \%)$ \\
\hline Relationship status & \\
\hline Single & $2(7 \%)$ & $14(47 \%)$ \\
\hline In a relationship & $12(44 \%)$ & $16(53 \%)$ \\
\hline Age $^{2}$ & $15(56 \%)$ & \\
\hline Median (IQR) $^{2}$ & $21(20-26)$ & $21(20-25)$ \\
\hline
\end{tabular}

${ }^{1}$ Chi-square of difference in dropout (full vs. half or none) non-significant $(p=0.3)$.

${ }^{2}$ Data shown for those with complete follow-up (both 2 and 4 weeks).

Table 2. Changes in WEMWBS scores, overall and stratified.

\begin{tabular}{|l|c|c|}
\hline & $\begin{array}{c}\text { Score difference } \\
(\mathbf{9 5 \%} \mathbf{C l})\end{array}$ & Interaction test \\
\hline Overall & $2.3(0.4$ to 4.2$)$ & n/a \\
\hline Gender & & \\
\hline Male & $2.8(-1.6$ to 7.2$)$ & \\
\hline Female & $2.5(0.4$ to 4.7$)$ & $\mathrm{p}=0.9$ \\
\hline Relationship status & & \\
\hline Single & $2.8(-0.0$ to 5.6$)$ & \\
\hline In a relationship & $1.8(-0.8$ to 4.4$)$ & $\mathrm{p}=0.6$ \\
\hline
\end{tabular}


Facebook use for two weeks. For comparison, a study examining a 12 week web-based cognitive behavioural tool to improve mental wellbeing in the general population found a 2.9 point difference using the same scale ${ }^{8}$. Our study supports the idea that associations reported in a previous study ${ }^{3}$ may in fact be causal.

The link between Facebook and mental wellbeing may be related to content perceived to be negative. A focus group found five main Facebook stressors: "managing inappropriate or annoying content, being tethered, lack of privacy and control, social comparison and jealousy, and relationship tension and conflict"'. In contrast, a study using Experience Sampling Methods found greater changes in self-esteem through text-based communications (including Facebook) than through face-to-face communication ${ }^{10}$. Differences in findings may be due to individual use patterns and feedback from other users ${ }^{11}$.

\section{Limitations}

Limitations include high dropout (possibly due to the lack of compensation) and a short follow-up period. Almost all students reported reduced Facebook use. Nevertheless, results could be affected by expectations, or perception of reduced use rather than actual changes in use.

\section{Conclusion}

Reducing Facebook use may be an effective intervention for improving mental wellbeing in university students. Future studies should examine effects in other participant groups, use longer follow-up periods, and consider deception to improve participant blinding.

\section{Data availability}

All collected data (excluding email addresses and names) are provided.

F1000Research: Dataset 1. Raw data of facebook and mental wellbeing analysis, 10.5256/f1000research.8835.d124806 ${ }^{12}$

\section{Consent}

Written informed consent for publication of their details was obtained from all participants.

\section{Competing interests}

No competing interests were disclosed.

\section{Grant information}

The author(s) declared that no grants were involved in supporting this work.

\section{Supplementary material}

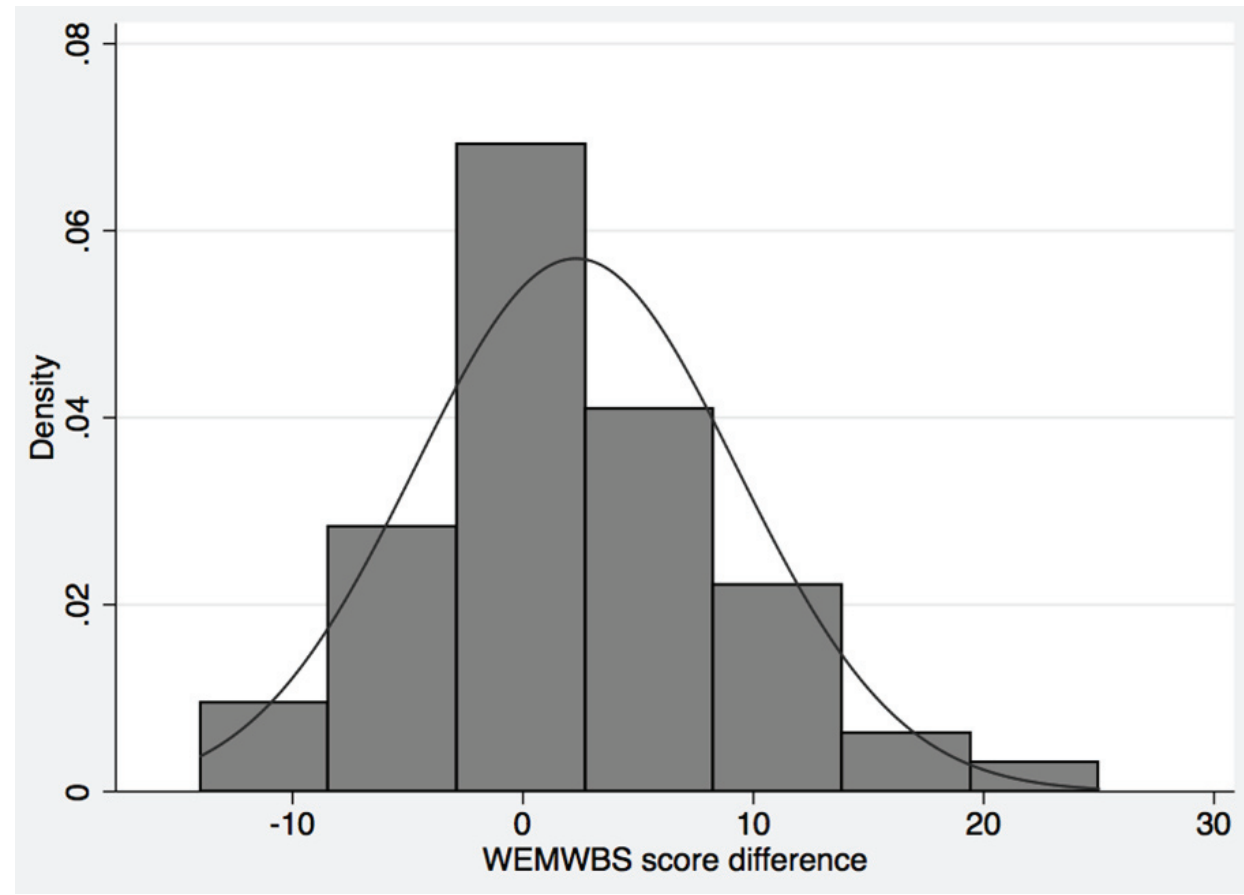

Supplementary figure 1. Distribution of differences in WEMWBS scores. 


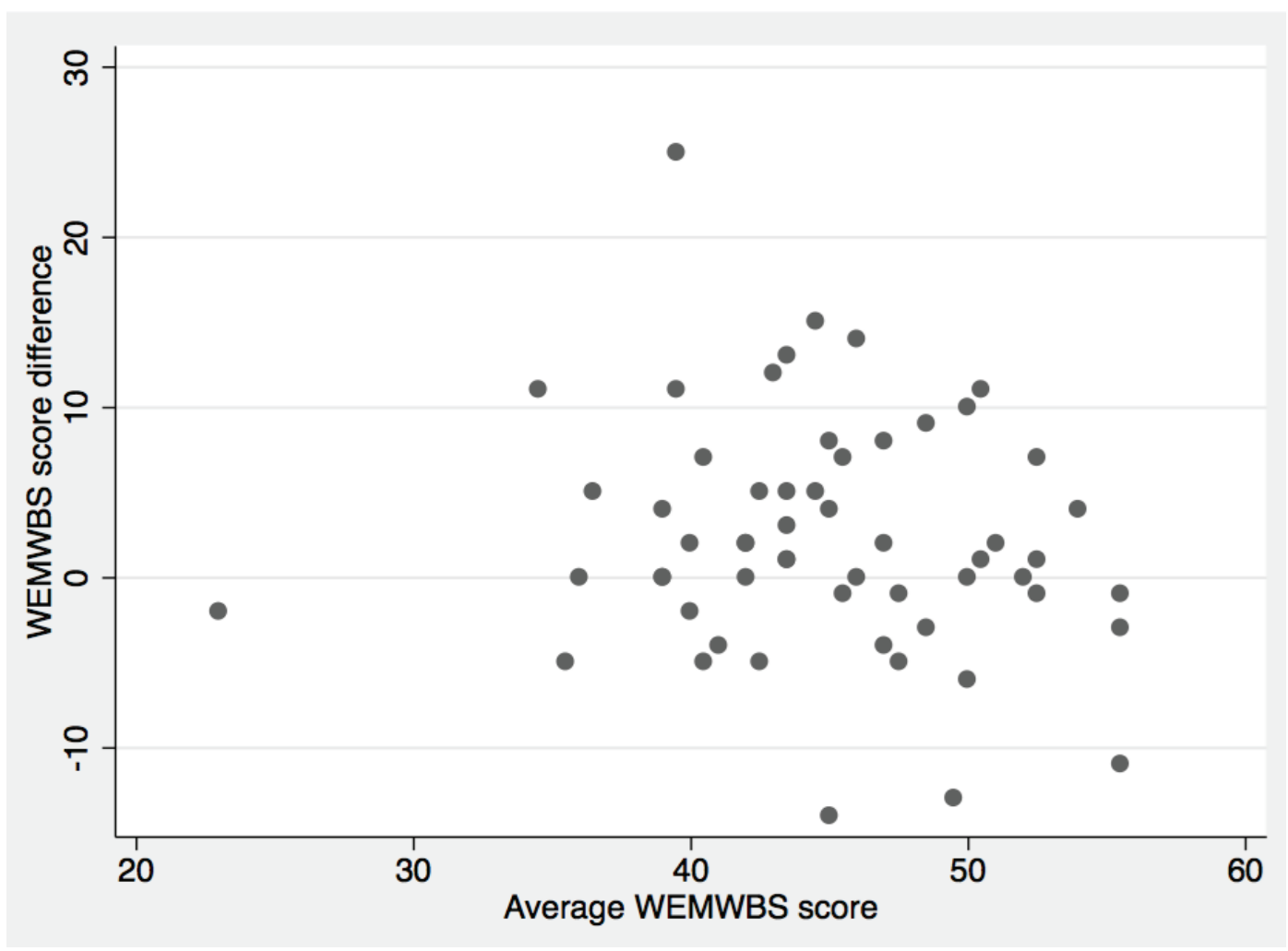

Supplementary figure 2. Difference in WEMWBS score against average scores.

1. Facebook Inc: Facebook Reports Fourth Quarter and Full Year 2013 Results. 2014; Accessed 13/08/14

Reference Source

2. Valenzuela S, Park N, Kee KF: Is There Social Capital in a Social Network Site?: Facebook Use and College Students' Life Satisfaction, Trust, and Participation'. J Comput Mediat Commun. 2009; 14(4): 875-901. Publisher Full Text

3. Kross $E$, Verduyn $P$, Demiralp $E$, et al.: Facebook use predicts declines in subjective well-being in young adults. PLOS One. 2013; 8(8): e69841. PubMed Abstract | Publisher Full Text | Free Full Text

4. Wilson RE, Gosling SD, Graham LT: A Review of Facebook Research in the Social Sciences. Perspect Psychol Sci. 2012; 7(3): 203-20. PubMed Abstract | Publisher Full Text

5. Tennant R, Hiller L, Fishwick R, et al.: The Warwick-Edinburgh Mental Well-being Scale (WEMWBS): development and UK validation. Health Qual Life Outcomes. 2007; 5(1): 63.

PubMed Abstract | Publisher Full Text | Free Full Text

6. Maheswaran $\mathrm{H}$, Weich $\mathrm{S}$, Powell J, et al.: Evaluating the responsiveness of the Warwick Edinburgh Mental Well-Being Scale (WEMWBS): group and individual level analysis. Health Qual Life Outcomes. 2012; 10(1): 156. PubMed Abstract | Publisher Full Text
7. StataCorp L: Stata User's Guide, Version 12. College Station, TX: Stata Press, StataCorp LP. 2011.

8. Powell J, Hamborg T, Stallard N, et al: Effectiveness of a web-based cognitivebehavioral tool to improve mental well-being in the general population: randomized controlled trial. J Med Internet Res. 2013; 15(1): e2.

PubMed Abstract | Publisher Full Text | Free Full Text

9. Fox J, Moreland JJ: The dark side of social networking sites: An exploration of the relational and psychological stressors associated with Facebook use and affordances. Comput Hum Behav. 2015; 45: 168-76.

Publisher Full Text

10. Gonzales AL: Text-based communication influences self-esteem more than face-to-face or cellphone communication. Comput Hum Behav. 2014; 39 : 197-203.

Publisher Full Text

11. Tobin SJ, Vanman EJ, Verreynne M, et al:: Threats to belonging on Facebook: lurking and ostracism. Soc Influ. 2015; 10(1): 31-42. Publisher Full Text

12. Wolf $\mathrm{A}$ : Dataset $\mathbf{1}$ in: Facebook and Mental Wellbeing: $\mathbf{A}$ crossover randomised controlled study. F1000Research. 2016. Data Source 


\section{Open Peer Review}

\section{Current Peer Review Status: ? X}

\section{Version 1}

Reviewer Report 09 December 2016

https://doi.org/10.5256/f1000research.9510.r17497

(C) 2016 Cash S. This is an open access peer review report distributed under the terms of the Creative Commons Attribution License, which permits unrestricted use, distribution, and reproduction in any medium, provided the original work is properly cited.

\section{Scottye J. Cash}

College of Social Work, The Ohio State Univeristy, Columbus, OH, USA

Thank you for asking me to review this manuscript. While the topic is interesting, the methods are limited, especially when considering the manuscript tried to make causal assertions. The methods were not very sophisticated and rather vague. Information on the sample was not included. There are many covariates (age, gender, year in school, length of time on Facebook, mental health history, etc.) that needed to be included in the analysis. The findings don't make a significant enough of an impact on the knowledge base.

Competing Interests: No competing interests were disclosed.

I confirm that I have read this submission and believe that I have an appropriate level of expertise to state that I do not consider it to be of an acceptable scientific standard, for reasons outlined above.

Reviewer Report 13 June 2016

https://doi.org/10.5256/f1000research.9510.r14288

(C) 2016 Uddin S. This is an open access peer review report distributed under the terms of the Creative Commons Attribution License, which permits unrestricted use, distribution, and reproduction in any medium, provided the original work is properly cited.

\section{Shahadat Uddin}

Faculty of Engineering \& Information Technology, University of Sydney, Sydney, NSW, Australia

The study is well designed and the author addressed the limitations and future research direction of the study very well. However, the manuscript lacks significantly in summarising previous research in align to this research. The author needs to describe a brief about the present 
status of literature in align to this study. Here is two examples of such literature:

Interconnected or disconnected? Promotion of mental health and prevention of mental disorder in the digital age (Hayes, Maughan \& Grant-Peterkin, 2016) ${ }^{1}$

Exploring physical, mental and psychological health for elders through their personal networks (Uddin \& Hossain, 2009) ${ }^{2}$

\section{References}

1. Hayes J, Maughan D, Grant-Peterkin H: Interconnected or disconnected? Promotion of mental health and prevention of mental disorder in the digital age. The British Journal of Psychiatry. 2016; 208 (3): 205-207 Publisher Full Text

2. Uddin MS, Hossain L: Exploring physical, mental and psychological health for elders through their personal networks. IEEE. 2009. Publisher Full Text

Competing Interests: No competing interests were disclosed.

I confirm that I have read this submission and believe that I have an appropriate level of expertise to confirm that it is of an acceptable scientific standard, however I have significant reservations, as outlined above.

The benefits of publishing with F1000Research:

- Your article is published within days, with no editorial bias

- You can publish traditional articles, null/negative results, case reports, data notes and more

- The peer review process is transparent and collaborative

- Your article is indexed in PubMed after passing peer review

- Dedicated customer support at every stage

For pre-submission enquiries, contact research@f1000.com

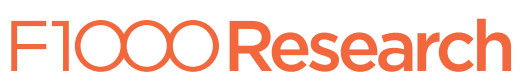

